\title{
Assessing changes in social determinants of health inequalities in South Africa : a decomposition analysis
}

\author{
Kehinde O. Omotoso ${ }^{*}$ (D) and Steven F. Koch
}

\begin{abstract}
Background: Despite various policy interventions that have targeted reductions in socio-economic inequalities in health and health care in post-Apartheid South Africa, evidence suggests that not much has really changed. In particular, health inequalities, which are strongly linked to social determinants of health (SDH), persist. This study, thus, examines how changes in the SDH have impacted health inequalities over the last decade, the second since the end of Apartheid.

Methods: Data come from information collected on social determinants of health (SDH) and on health status in the 2004, 2010 and 2014 questionnaires of the South African General Household Surveys (GHSs). The health indicators considered include ill-health status and disability. Concentration indices and Oaxaca-Blinder decomposition of change in a concentration index methods were employed to unravel changes in socio-economic health inequalities and their key social drivers over the studied time period.

Results: The results show that inequalities in ill-health are consistently explained by socio-economic inequalities relating to employment status and provincial differences, which narrowed considerably over the studied periods. Relatedly, disability inequalities are largely explained by shrinking socio-economic inequalities relating to racial groups, educational attainment and provincial differences.

Conclusion: The extent of employment, location and education inequalities suggests the need for improved health care management and further delivery of education and job opportunities; greater effort in this regard is likely to be more beneficial in some way.
\end{abstract}

Keywords: Decomposition, Health inequality, Self-assessed health, Social determinants, South Africa

\section{Background}

Globally, policymakers and researchers have long sought not only to improve overall population health and reduce burden of disease, ill-health and disability, but also to reduce or eliminate health differentials, based on gender, geography, race, ethnicity and socio-economic status, amongst others [1-7]. To this effect, various governments, at different capacities, have enacted policies and reforms to tackle health inequality and its social determinants [8]. Despite considerable attention on socio-economic related health inequalities, striking differences in health still exist within and among nations, today. Socio-economic related

*Correspondence: jewelslife2003.ko@gmail.com;kehinde.omotoso@up.ac.za Department of Economics, University of Pretoria, Private Bag X20, Hatfield 0028, Pretoria, South Africa

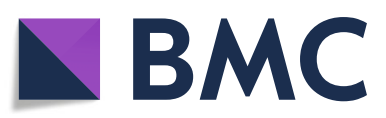

(C) The Author(s). 2018 Open Access This article is distributed under the terms of the Creative Commons Attribution 4.0 International License (http://creativecommons.org/licenses/by/4.0/), which permits unrestricted use, distribution, and reproduction in any medium, provided you give appropriate credit to the original author(s) and the source, provide a link to the Creative Commons license, and indicate if changes were made. The Creative Commons Public Domain Dedication waiver (http://creativecommons.org/publicdomain/zero/1.0/) applies to the data made available in this article, unless otherwise stated. 
Post 1994, the South African health system has developed into a two-tiered system which is unified and more co-ordinated. The National health plan, developed by the African National Congress (ANC) in 1994, charted a new path for a codified and a more coherent health system [22]. Primary health care (PHC) was made the cornerstone of health policy, with the introduction of free medical treatment for pregnant women and children younger than 6 years in 1994 and 1996, and subsequent extension to all users. The 14 fragmented health departments were also consolidated into one national and nine provincial health departments. Driven by the need to redress inequities and discriminations, the health system is being transformed, through different documented reforms, polices and programmes (including the on-going implementation of the national health insurance (NHI) scheme) [21, 23-31], into an integrated and comprehensive health care system.

The health care system, which provides services for an estimated population of over 58 million people, comprises the private and public sectors. Basically, South Africa's public health care system contains five layers, namely: primary health care (clinics), district hospitals, regional hospitals, tertiary/academic hospitals and central/academic hospitals. This structure was developed to address cost effective health care for all citizens, on an appropriate level, and to ensure better health for all. The majority of the population access health services through government-run and funded public clinics and hospitals. The public health services are divided into primary, secondary and tertiary through health facilities that are located in, and managed by, the provincial departments of health [32].

South Africa is committed to the health of her citizens and equitable access to better health care services [33]. This right to health is deeply rooted in post-apartheid South Africa's constitution, which specifies that 'everyone has the right to have access to health care services, including reproductive health care' [34]. Thus, everyone has access to both the public and private health services. However, access to private health services depends largely on an individual's ability to pay: individuals can either choose to pay out-of-pocket or purchase private insurance in order to be treated at private hospitals and health clinics. Public health care provides mostly free services and care to all citizens, including pharmaceuticals, wheelchairs and crutches, and home care visits, amongst others. However, public health care is often characterised by problems, such as long waiting times, rushed appointments, old facilities, poor disease control and prevention practices, and poor quality of care, when compared to private health care $[32,35]$.

In post-apartheid South Africa, improving health outcomes is prioritised in health and cognate policies and reforms. At the core of these policies and reforms is the continuous fight against the quadruple burden of disease, namely HIV/AIDS and TB, maternal, infant and child mortality, non-communicable/chronic diseases, ill-health/injury and violence that plague the country $[36,37]$. Although enormous effort has gone into addressing each of this burden of disease, it remains a challenge to the public health system [29]. This burden of disease is closely associated with the vast socio-economic inequalities that characterise the country, known as one of the most unequal in the world [38-40], even as the government fights against social injustice and socio-economic inequalities in all facets of life. Thus, addressing social determinants of health has been a cornerstone in primary health care (PHC), its re-engineering strategy [41], and the National Development Plan (NDP).

\section{Policy context}

Since the emergence of democracy in the last two decades in South Africa, considerable effort has gone into redressing the damaging impacts of Apartheid, which was characterised by legislated inequality. Specifically, the South African government has embarked on a variety of policies and reforms to reverse the discriminatory practices that pervaded all aspects of life before 1994 [42]. Policy interventions have targeted reductions in socio-economic inequalities in various capacities, and, by extension, these policies have also applied to the health care system: fiscal redistribution targeted at health, education, social protection sectors; abolition of user fees at the primary health care (PHC) level in 1994; extension of PHC policy to all users in relatively poorer households in 1996; introduction of Government Employees MedicalAid Scheme (GEMS) in 2006 and ongoing discussions related to universal health care coverage through yet-to-be-fully-implemented national health insurance (NHI) [23-25, 28, 43, 44]. However, evidence suggests that not much has really changed [32, 45-47]. In particular, health inequalities, which are strongly linked to social determinants of health (SDH), persist [48-50]. To further address socio-economic related health inequalities, a broader understanding of the changes that have occurred over the post-apartheid period might be insightful.

\section{Problem statement}

In the literature, health inequality and its social determinants have received considerable attention $[18,21,23,33,35,48,50-58]$. Some of the preceding studies find poor self-reported health to be higher among lower socio-economic groups [50, 51, 55]. One study finds that the burdens of major categories of selfreported illness and disability are greater among lower socio-economic groups [50]. In a related study, social protection and employment, knowledge and education, 
housing and infrastructure contribute to disparities in good self assessed health (SAH) [48]. Moreover, there is strong indirect racial aspect to health inequalities in South Africa [57].

However, the existing empirical analysis of health inequality is, to a large extent, cross-sectional. It focuses at a given point in time and might apply one-way decomposition to examine the contributions of socio-economic factors to health inequality. Moreover, they tend to focus on only a few health indicators. With few indicators, we may only see narrow view of health inequalities and, thus, may underestimate overall health inequality. Single-time assessment of health inequality, on the other hand, may downplay the effects of health inequality-focused reforms, as it does not uncover dynamics that are vital for indirect assessment of the effectiveness, or otherwise, of prior policies and health interventions aimed at reducing socioeconomic related health inequalities. For instance, one recent study with cross-sectional one-way decomposition explains the social factors that account for health disparities [48]. It is relevant for understanding health inequalities in South Africa, but only provides information about health inequality at a given point in time. It cannot uncover changes in health inequalities. Yet, it is important to understand those changes and the extent to which they have been impacted by, for example, changes in social factors, especially in a country such as South Africa, which has worked and is still working to redress socio-economic related health inequalities by targeting key social factors. Doing so can help to identify key drivers of changes in health inequality and, thus, improve the efficiency of resource allocations to further reduce health inequalities. Moreover, areas that need further improvement or interventions can be highlighted. It can also serve as feedback during the policy review process, especially when considering reforms directed at socio-economic factors that are often targeted by policy.

To consider these dynamic aspects, we make use of existing methodological developments in the literature to extend previous analyses $[48,50]$, which we discuss below. The data used in our analysis was sourced from the 2004, 2010 and 2014 General Household Surveys (GHSs). The initial year, 2004 marks the recommendation for the implementation of National Health Insurance in South Africa [44] and coincides with the 10 year anniversary of the end of Apartheid; 2014 marks an additional decade down the line, while 2010 indicates the enactment of key policies, programmes and service priorities to reduce the burden of premature death and improve equity, efficiency and quality of health care in the South African health system [43]. Therefore, the analysis allows us to correlate health policies from the second decade post-apartheid, indirectly, with either a widening or narrowing of health inequality.
Our empirical strategy adopts the concentration index regression model and Oaxaca-type decomposition of change in the concentration index $[59,60]$. The concentration index method was employed to uncover the relative change in health inequalities over the studied periods, linking those changes to changes in the SDH. The decomposition of change in the concentration index explains how changes in health inequalities are attributable to changes in social determinants. We apply the method to ill-health status and disability.

\section{Methods}

\section{Data source}

Data used in this study was sourced from three waves of South African General Household Surveys (GHSs); one from 2004 [61], another from 2010 [62] and the other from 2014 [63]. Although GHS data exist for 2002 and 2003, the 2004 survey was chosen because 2004 marks the beginning of the second decade of democracy, while 2014 represents the end of that decade. Although a fiveyear step would be more obvious, we decide to use 2010 because the survey questions were consistent with the other two surveys, which was not the case with 2009. The GHSs are repeated cross-sectional household surveys collected annually by the national statistical agency, Statistics South Africa (StatsSA), with new samples drawn each year. Each year, the sample includes approximately 30,000 households, following a multi-stage stratified design, such that, each sample is representative at both the national and provincial levels within any year. The surveys collect a range of demographic and socio-economic information on households and individuals across the country's nine provinces. Survey questions relate to housing services, social services, socio-demographic information, labour markets, health and health care information and household tourism activities. Population weights are available in the surveys for both households and individuals. To account for the different survey designs among the datasets, we use the adjusted survey weights provided by StatsSA.

\section{Variables definition and measurement}

Health data are based on a short series of questions covering illnesses or injuries during the past 30 days prior to the survey, categories of disease/illness, dysfunctional disability lasting six months or more, categories of disabilities, whether an individual had access to medical aid coverage and the type of health care facility (public or private) where care would be sought in the event of illness. For a holistic outlook on health inequality, information related to health status in the two surveys were considered in our analysis.

Health status is measured by ill-health and disability. In the surveys, ill-health status is based on whether or not the 
respondent suffered from any illness or injury during the past month. Each respondent was asked whether he/she is limited in his/her daily activities, at home, at work or at school, because of a long-term physical, sensory, hearing, intellectual, or psychological condition, lasting six months or more. Positive responses are defined as disabled. Even though the GHS has some limitations, in that it does not contain explicit information on SAH and quality of health care, we use the information on ill-health/injury, which has been identified to be an important predictor of morbidity or mortality, especially in developing countries [64, 65].

Social determinants of health included in our analysis are based on WHO identified domains that influence pro-equity progress towards universal health care. Some of the domains include income and poverty, knowledge and education, housing and infrastructure, social protection, gender norms, and other individual/household factors [48]. Information collected in the GHS that is in line with the WHO identified domains on SDH, consistent in all surveys, and thus, used in our analysis includes: employment status; social grant recipient status; highest level of education completed (no schooling, less than diploma, diploma/certificate, university degree, and postgraduate degree); province and urban/rural setting; age; gender; race (black Africans, coloured, Asian/Indian and white), marital status (married, widow/widower, divorced/separated and single), and social grants/assistance receipt status.

Socio-economic variables such as education, social grants and employment were not just included in the analysis on the basis of WHO identified domains or data availability, but were included to capture the realities of changes in the socio-economic outlook of the country. For instance, since the emergence of democracy in South Africa, policy redressing all forms of socio-economic related inequalities were enacted, creating a more equitable national system. These policies improved access to education, social grants, employment, housing and health care, especially for the previously disadvantaged (nonwhite) groups. Over the post-apartheid period, there has been a relative increase in receipt of formal education and social grants by black Africans. In particular, the noncontributory old age pension and child grant have a strong racial dimension, with a considerable proportion of black Africans and coloureds as beneficiaries $[66,67]$.

Moreover, the GHS includes information on the ownership of household assets and services. We use that information to construct a wealth index, which serves as a proxy for our measure of socio-economic status; in the absence of data on household income. Following $[68]^{1}$, a wealth index was constructed in each of the survey years using the method of factor analysis (FA) ${ }^{2}$ on a set of seven variables measuring relative wealth; source of drinking water, presence of electricity, land line/cellular phone, television set, radio, refrigerator and car. Thus, we were limited to wealth-related questions that were available in all surveys. Furthermore, this is our measure of socio-economic status.

\section{Empirical methods of estimating health inequality Estimating a concentration index}

As suggested earlier, we use the concentration index $(C I)$ and decomposition of change in the concentration index for the analysis. The concentration index is employed because it presents an accurate picture of socio-economic inequalities in health, and has been used in a number of related studies [69-75].

For our empirical estimation, the standard concentration index is defined as twice the covariance between our health variable $(H)$, e.g ill-health, and the ranking of socioeconomic status $(S)$ divided by the mean of the health variable, $\mu[69,70,76]$ :

$$
C I=\frac{2}{\mu} \operatorname{cov}(H, S) \text {. }
$$

It can also be written as :

$$
C I=\frac{2}{n \mu}\left[\sum_{i=1}^{n} H_{i} S_{i}\right]-1 .
$$

where $\mu$ is the mean of $H_{i}$; $S_{i}$ is the fractional rank of the $i$ th individual in the socio-economic groupings; $C I$ is the concentration index which is the measure of relative inequality, such that doubling the health variable leaves $C I$ unchanged. $C I$ takes a value of zero when a health variable takes the same value among all individuals irrespective of their socio-economic status; $C I$ is negative when a health variable is more concentrated among the poor than the better-off, and vice versa.

For ease of computation and generation of standard errors, from which statistical inferences can be made, the $C I$ is specified as a regression:

$$
2 \sigma_{s}^{2}\left(\frac{H_{i}}{\mu}\right)=\alpha+\beta S_{i}+\sum_{j} \beta_{j} X_{j i}+v_{i} .
$$

where $\sigma_{s}^{2}$ is the variance of the fractional rank; $\alpha$ is the intercept; $\beta$ is an estimate of the $C I ; \beta_{j}$ are the parameter vectors of the determinants $X_{j}$; and $v_{i}$ is the error term.

\section{Decomposing a change in concentration index}

The concentration index of a health variable can be decomposed into the contributions of individual factors to its inequality, where each contribution is the product of the sensitivity of the health variable with respect to that factor and the degree of inequality in that factor [60].

Our decomposition analysis relies on modeling the linear relationship between a health variable of interest, $H$, and the contributions of the $j$ determinants, $X_{j}$ : 


$$
H=\alpha+\sum_{j} \beta_{j} X_{j}+v
$$

where $\beta_{j}$ are the parameters' coefficients of $X_{j}$, and $v$ is the error term. By substituting (4) into (2), the overall concentration index $(C I)$ can be rewritten as a linear combination of the concentration indices of the determinants, plus an error term, as expressed :

$$
C=\sum_{j}\left(\frac{\beta_{j} \bar{X}_{j}}{\mu}\right) C_{j}+\frac{G C_{v}}{\mu} .
$$

where $\mu$ is the mean of health variable, $H$; $\bar{X}_{j}$ is the mean of each $j$ determinant; $C_{j}$ is the concentration index for the $j t h$ determinants, calculated from (2) by replacing the health variable $\left(H_{i}\right)$ with the determinant $\left(X_{j}\right)$ (defined analogously to $C$ ); $G C_{v}$ is the generalised concentration index for the error term $(v)$, and $C$ is made up of two components (5). The first is the explained component, which is equal to a weighted sum of the concentration indices of the $j$ regressors, where the weight is simply the elasticity of $H$ with respect to $X_{j}\left(\eta_{j}=\beta_{j} \frac{\bar{X}_{j}}{\mu}\right)$. The second is the unexplained component, captured by the last term, $\frac{G C_{v}}{\mu}$; it is the inequality in health that cannot be explained by systematic variation across income groups in the $X_{j}$.

As opposed to the cross-sectional decomposition above, it is possible to decompose health inequalities over time [60]. Specifically, one can unravel correlates of changes in health inequalities over time, by applying the Oaxaca-type decomposition [59].

To model the decomposition of change in the health inequalities across time, we apply the Oaxaca decomposition of change method to (5):

$$
\Delta C=\sum_{j} \eta_{j t}\left(C_{j t}-C_{j t-1}\right)+\sum_{j} C_{j t-1}\left(\eta_{j t}-\eta_{j t-1}\right)+\Delta\left(\frac{G C_{v t}}{\mu_{t}}\right) .
$$

where $t$ refers to time period and $\Delta$ denotes first differences. In (6), we weight the difference in concentration indices by the second period elasticity and weight the difference in elasticities by the first period concentration index. An alternative to (6) would be to weight the difference in concentration indices by the first period elasticity and weight the difference in elasticities by the second period concentration index as expressed in (7):

$$
\Delta C=\sum_{j} \eta_{j t-1}\left(C_{j t}-C_{j t-1}\right)+\sum_{j} C_{j}\left(\eta_{j t}-\eta_{j t-1}\right)+\Delta\left(\frac{G C_{v t}}{\mu_{t}}\right) .
$$

As indicated earlier, this decomposition allows one to decompose the change in SES-related inequality in a health variable into changes in inequalities in its determinants, on one hand, and changes in the elasticities of the health variable with respect to these determinants, on the other hand. Our empirical estimation follows this approach in explaining changes in SES-related inequalities in health over time. Estimates were based on linear probability models (LPMs), which are appropriately weighted to the population and robust to heteroskedasticity. LPMs were employed due to the binary nature of the dependent health variables of interest.

One key assumption underlying the method is that there must be a consistent measure of socio-economic status, and population must be observed at least in two different points in time. In our analysis, the measure of socioeconomic status is the wealth index, while we apply the method using three different time periods; 2004, 2010 and 2014. Data were analysed using Stata 14 [77].

\section{Results \\ Data summary}

Table 1 presents the data summaries by survey year. The results are presented in terms of the relative proportions of observations across the survey years. Compared with the 2004 and 2010 surveys, the 2014 survey contained fewer individuals aged less than 30 years, females and white. However, it contained more black Africans. The 2004 survey comprised more individuals below 30 years of age, females, coloured, white and single, while more married individuals are contained in the 2010 survey. Notably, the 2014 survey had more educated individuals with diplomas or certificates and an honours degree, but fewer people having no formal education. In comparison with 2004 and 2010, 2014 data is less rural, with fewer individuals living in the Eastern Cape, Northern Cape, Free State, Kwazulu-Natal and Limpopo, while more individuals are living in the relatively richer provinces of Western Cape and Gauteng. Moreover, social grant beneficiaries have greater coverage, while unemployment rates are lower in 2004 than in 2014. The results further suggest that the surveys contained similar proportions of Indians, as well as those who live in the Northwest and Mpumalanga provinces in 2004, 2010 and 2014.

Compared with 2004 and 2010, health status in 2014 is better, as a lower share of individuals reported ill-health. On the contrary, there is a sharp increase in disability reports in 2010. Similarly, medical aid coverage rates are proportionately higher in 2010, than in 2004 and 2014. However, fewer individuals prefer to utilise public health care when ill in 2010, while proportionally more individuals would prefer private health care in 2014, than in previous studied periods.

\section{Health concentration indices for 2004, 2010 and 2014}

Table 2 presents the health concentration indices for 2004, 2010 and 2014 (estimates are from (3)). The results show the relative changes in health inequalities over the different time periods. Ill-health is more concentrated 
Table 1 Summary statistics (mean) of the dependent and independent variables, GHS 2004, 2010 and 2014

\begin{tabular}{|c|c|c|c|}
\hline Variable & 2004 & 2010 & 2014 \\
\hline $0-5 y r s$ & 0.130 & 0.125 & 0.118 \\
\hline $6-17 y r s$ & 0.257 & 0.238 & 0.227 \\
\hline $18-30 \mathrm{yrs}$ & 0.249 & 0.244 & 0.242 \\
\hline $31-45$ yrs & 0.194 & 0.205 & 0.215 \\
\hline $46-64$ yrs & 0.127 & 0.139 & 0.146 \\
\hline 65 yrs + & 0.043 & 0.048 & 0.053 \\
\hline Female & 0.517 & 0.514 & 0.512 \\
\hline Black Africans & 0.783 & 0.793 & 0.800 \\
\hline Coloured & 0.091 & 0.090 & 0.090 \\
\hline Indian & 0.025 & 0.025 & 0.025 \\
\hline White & 0.101 & 0.091 & 0.085 \\
\hline Married & 0.272 & 0.278 & 0.276 \\
\hline Single & 0.728 & 0.720 & 0.722 \\
\hline No schooling & 0.195 & 0.167 & 0.149 \\
\hline Less than diploma & 0.740 & 0.753 & 0.746 \\
\hline Diploma/certificate & 0.036 & 0.035 & 0.041 \\
\hline Honours degree & 0.020 & 0.030 & 0.035 \\
\hline Postgraduate & 0.004 & 0.003 & 0.004 \\
\hline Employed & 0.308 & 0.286 & 0.306 \\
\hline Urban & 0.563 & 0.614 & 0.638 \\
\hline Western Cape & 0.107 & 0.111 & 0.114 \\
\hline Eastern Cape & 0.135 & 0.128 & 0.124 \\
\hline Northern Cape & 0.023 & 0.022 & 0.022 \\
\hline Free state & 0.058 & 0.054 & 0.051 \\
\hline Kwazulu-Natal & 0.202 & 0.199 & 0.197 \\
\hline Northwest & 0.068 & 0.068 & 0.068 \\
\hline Gauteng & 0.224 & 0.235 & 0.242 \\
\hline Mpumalanga & 0.078 & 0.078 & 0.078 \\
\hline Limpopo & 0.106 & 0.105 & 0.104 \\
\hline Grant recipients & 0.098 & 0.275 & 0.290 \\
\hline Illness & 0.113 & 0.113 & 0.097 \\
\hline Disability & 0.026 & 0.080 & 0.031 \\
\hline Medical aid coverage & 0.156 & 0.180 & 0.179 \\
\hline Public health facility & 0.751 & 0.730 & 0.734 \\
\hline \multirow[t]{2}{*}{ Private health facility } & 0.248 & 0.253 & 0.262 \\
\hline & Mean & Mean & \\
\hline Observations & 97,036 & 95,764 & 92,445 \\
\hline
\end{tabular}

Estimates are weighted to the population using the sample weights

among the poor in 2010, but more concentrated among the better-off in 2004 and 2014; however, the result is not significant at conventional levels in 2014. Similarly, disability is somewhat more concentrated among the poor in 2004 and 2010, while it is more concentrated among the better-off in 2014, although the results are not statistically significant in 2004 and 2010.

Ill-health concentration indices for 2004 and 2010 were 0.018 and -0.017 , respectively, indicating a concentration of ill-health amongst the poor over time, and an increase in inequality between 2004 and 2010. Similarly, disability concentration indices for 2004 and 2010 were -0.000 and -0.004 , respectively, suggesting that disability was more concentrated among the poor in each, and a worsening in inequality between the time period. Between 2004 and 2010, changes in ill-health and disability concentration indices were -0.035 and -0.004 , respectively. These changes are pro-poor and widened over that time period. On the contrary, the concentration indices for ill-health and disability changed by 0.026 and 0.037 over the period 2010 and 2014, suggesting that they become more concentrated among the better-off. In what follows (see Table 3), we present the results of the social determinants that contribute to the observed changes in the health concentration indices. Each row in Table 3 was estimated based on the calculations from (6). In presenting the results, we emphasise variables whose socio-economic inequalities have consistently reduced health inequalities over the periods.

The results further suggest that, in all the survey years, ill-health is less concentrated among the relatively younger individuals, when compared with those aged above 65 years. Similarly, those living in the Western Cape and KwaZulu-Natal provinces report illness less often. Furthermore, those who are relatively educated and employed are less likely to report disability, while the opposite was observed for females and those without formal education. We find disability to be less concentrated among those who are educated and employed in 2004, 2010 and 2014. Disability is also found to be less concentrated among residents of relatively urban provinces. However, single individuals, those without formal education and social grant recipients are more likely to suffer from disability; such a result is expected, since one of the social grants is a disability grant.

\section{Decomposition result}

In Table 3, we present the Oaxaca decomposition results for the health indicators, separately, for 2004-2010 and 2010-2014, respectively. These results show the extent to which inequalities in the health indicators are due to changes in socio-economic inequalities in their associated social determinants. While interpreting these results, one needs to bear in mind that our proxy for socioeconomic status is wealth, and ill-health and disability inequalities relatively worsened (became more pro-poor) over the period 2004-2010, while the inequalities narrowed (became more pro-rich) between 2010-2014. Each 
Table 2 Health Concentration Indices and Social Determinants for 2004, 2010 and 2014, GHS South Africa

\begin{tabular}{|c|c|c|c|c|c|c|c|c|c|c|c|c|}
\hline & \multicolumn{6}{|c|}{ III-health status } & \multicolumn{6}{|l|}{ Disability } \\
\hline & \multicolumn{2}{|l|}{2004} & \multicolumn{2}{|l|}{2010} & \multicolumn{2}{|l|}{2014} & \multicolumn{2}{|l|}{2004} & \multicolumn{2}{|l|}{2010} & \multicolumn{2}{|l|}{2014} \\
\hline & Coeff & se & Coeff & se & Coeff & se & Coeff & se & Coeff & se & Coeff & se \\
\hline $\mathrm{Cl}$ & $0.018^{*}$ & $(0.008)$ & $-0.017^{*}$ & $(0.008)$ & 0.009 & $(0.010)$ & -0.000 & $(0.016)$ & -0.004 & $(0.008)$ & $0.033^{*}$ & $(0.014)$ \\
\hline $0-5 y r s$ & $-0.136^{* * *}$ & $(0.015)$ & $-0.156^{* * *}$ & $(0.013)$ & 0.025 & $(0.013)$ & $-0.377^{* * *}$ & $(0.036)$ & $0.351^{* * *}$ & $(0.018)$ & $-0.673^{* * *}$ & (0.039) \\
\hline $6-17 y r s$ & $-0.211^{* * *}$ & $(0.013)$ & $-0.207^{* * *}$ & $(0.012)$ & $-0.054^{* * *}$ & $(0.011)$ & -0.038 & $(0.032)$ & $-0.181^{* * *}$ & $(0.013)$ & $-0.432^{* * *}$ & $(0.029)$ \\
\hline $18-30 y r s$ & $-0.207^{* * *}$ & $(0.013)$ & $-0.187^{* * *}$ & $(0.013)$ & $-0.067^{* * *}$ & $(0.012)$ & 0.059 & $(0.033)$ & $-0.129 * * *$ & $(0.014)$ & $-0.327^{* * *}$ & $(0.031)$ \\
\hline $31-45$ yrs & $-0.126^{* * *}$ & $(0.013)$ & $-0.132^{* * *}$ & $(0.013)$ & $-0.042^{* * *}$ & $(0.012)$ & $0.247^{* * *}$ & $(0.034)$ & $-0.097^{* * *}$ & $(0.014)$ & $-0.269^{* * *}$ & $(0.030)$ \\
\hline $46-64$ yrs & $-0.047^{* * *}$ & $(0.013)$ & $-0.052^{* * *}$ & $(0.013)$ & $-0.028^{*}$ & $(0.012)$ & $0.384^{* * *}$ & $(0.036)$ & $-0.067^{* * *}$ & $(0.014)$ & $-0.211^{* * *}$ & $(0.030)$ \\
\hline Female & $0.019^{* * *}$ & $(0.004)$ & $0.028^{* * *}$ & $(0.004)$ & $0.030^{* * *}$ & $(0.004)$ & $-0.129 * * *$ & $(0.009)$ & $-0.012^{* *}$ & $(0.004)$ & -0.004 & $(0.007)$ \\
\hline Black African & -0.014 & $(0.008)$ & -0.010 & $(0.008)$ & -0.003 & $(0.008)$ & $-0.090 * * *$ & $(0.019)$ & -0.010 & $(0.008)$ & -0.016 & $(0.014)$ \\
\hline Indian/Asians & -0.001 & $(0.015)$ & 0.006 & $(0.014)$ & $-0.045^{* *}$ & $(0.015)$ & -0.001 & $(0.032)$ & -0.003 & $(0.015)$ & -0.008 & $(0.024)$ \\
\hline White & $-0.025^{*}$ & $(0.011)$ & -0.001 & $(0.011)$ & $0.053^{* * *}$ & $(0.012)$ & -0.025 & $(0.021)$ & 0.002 & $(0.010)$ & 0.023 & $(0.018)$ \\
\hline Single & $0.012^{*}$ & $(0.006)$ & $0.014^{*}$ & $(0.006)$ & -0.000 & $(0.006)$ & $0.171^{* * *}$ & $(0.014)$ & $0.029 * * *$ & $(0.004)$ & $0.074^{* * *}$ & $(0.009)$ \\
\hline No Schl. & 0.031 & $(0.026)$ & $0.064^{* * *}$ & $(0.016)$ & $0.046^{* *}$ & $(0.017)$ & 0.120 & $(0.065)$ & $0.070^{* * *}$ & $(0.021)$ & $0.179 * * *$ & $(0.041)$ \\
\hline Less Diploma & 0.008 & $(0.025)$ & $0.042^{* *}$ & $(0.014)$ & -0.006 & $(0.014)$ & $-0.213^{* * *}$ & $(0.059)$ & $-0.075^{* * *}$ & $(0.017)$ & $-0.166^{* * *}$ & $(0.028)$ \\
\hline Diploma Cert. & 0.017 & $(0.027)$ & $0.051^{* *}$ & $(0.019)$ & 0.007 & $(0.017)$ & $-0.237^{* * *}$ & $(0.060)$ & $-0.063^{* * *}$ & $(0.019)$ & $-0.184^{* * *}$ & $(0.030)$ \\
\hline Honours degree & 0.001 & $(0.031)$ & $0.046^{*}$ & $(0.020)$ & 0.007 & $(0.019)$ & $-0.278^{* * *}$ & $(0.058)$ & $-0.069^{* * *}$ & $(0.018)$ & $-0.201^{* * *}$ & $(0.030)$ \\
\hline Employed & -0.003 & $(0.005)$ & $-0.013^{*}$ & $(0.005)$ & 0.003 & $(0.006)$ & $-0.229^{* * *}$ & $(0.010)$ & $-0.035^{* * *}$ & $(0.004)$ & $-0.081^{* * *}$ & $(0.008)$ \\
\hline Urban & 0.008 & $(0.005)$ & $0.039^{* * *}$ & $(0.005)$ & $0.036^{* * *}$ & $(0.005)$ & 0.004 & $(0.010)$ & 0.007 & $(0.005)$ & 0.009 & $(0.009)$ \\
\hline Western Cape & $-0.102^{* * *}$ & $(0.010)$ & $-0.021^{*}$ & $(0.009)$ & $-0.044^{* * *}$ & $(0.010)$ & 0.048 & $(0.025)$ & $-0.056^{* * *}$ & $(0.010)$ & -0.028 & $(0.018)$ \\
\hline Eastern Cape & $-0.055^{* * *}$ & $(0.009)$ & $-0.054^{* * *}$ & $(0.008)$ & $0.030^{* *}$ & $(0.010)$ & 0.012 & $(0.017)$ & -0.002 & $(0.010)$ & $-0.041^{*}$ & $(0.017)$ \\
\hline Northern Cape & $-0.085^{* * *}$ & $(0.011)$ & $0.026^{*}$ & $(0.010)$ & 0.015 & $(0.011)$ & -0.019 & $(0.023)$ & $0.030^{* *}$ & $(0.011)$ & $0.044^{*}$ & $(0.023)$ \\
\hline KwaZulu - Natal & $-0.114^{* * *}$ & $(0.009)$ & $-0.035^{* * *}$ & $(0.008)$ & $-0.043^{* * *}$ & $(0.009)$ & -0.002 & $(0.017)$ & $-0.050^{* * *}$ & $(0.009)$ & $-0.072^{* * *}$ & $(0.016)$ \\
\hline North West & -0.009 & $(0.010)$ & 0.000 & $(0.009)$ & 0.009 & $(0.011)$ & 0.026 & $(0.020)$ & $-0.024^{*}$ & $(0.010)$ & 0.038 & $(0.020)$ \\
\hline Gauteng & $-0.054^{* * *}$ & $(0.009)$ & $-0.019^{*}$ & $(0.008)$ & $0.029^{* *}$ & $(0.010)$ & -0.001 & $(0.016)$ & $-0.105^{* * *}$ & $(0.008)$ & $-0.054^{* * *}$ & $(0.015)$ \\
\hline Mpumalanga & -0.012 & $(0.010)$ & -0.014 & $(0.008)$ & $0.021^{*}$ & $(0.010)$ & 0.018 & $(0.019)$ & $-0.084^{* * *}$ & $(0.009)$ & $-0.056^{* *}$ & $(0.017)$ \\
\hline Limpopo & $-0.061^{* * *}$ & $(0.009)$ & 0.010 & $(0.009)$ & $-0.023^{*}$ & $(0.010)$ & $-0.038^{*}$ & $(0.018)$ & 0.017 & $(0.010)$ & $-0.065^{* * *}$ & $(0.018)$ \\
\hline Grant recipients & $0.093^{* * *}$ & $(0.008)$ & $0.020^{* * *}$ & $(0.005)$ & -0.004 & $(0.007)$ & $0.557^{* * *}$ & $(0.028)$ & $0.141^{* * *}$ & $(0.007)$ & $0.291^{* * *}$ & $(0.015)$ \\
\hline Constant & $0.346^{* * *}$ & $(0.031)$ & $0.257^{* * *}$ & $(0.022)$ & $0.162^{* * *}$ & $(0.021)$ & $0.286^{* * *}$ & $(0.072)$ & $0.285^{* * *}$ & $(0.025)$ & $0.543^{* * *}$ & $(0.045)$ \\
\hline Adjusted $R^{2}$ & 0.03 & & 0.02 & & 0.02 & & 0.07 & & 0.19 & & 0.05 & \\
\hline Observation & 97,036 & & 95,764 & & 92,445 & & 97,036 & & 95,764 & & 92,445 & \\
\hline
\end{tabular}

Standard errors reported in parentheses

${ }^{*} p<0.05,{ }^{* *} p<0.01,{ }^{* * *} p<0.001$

row in Table 3 is thus interpreted in terms of its socioeconomic contribution to the observed changes in the health inequalities, over time. A negative sign on a variable denotes that the contribution of the socio-economic inequality in that variable worsens health inequalities over the period 2004-2010, while a positive sign indicates that socio-economic inequality, probably reduced, and thus such variable contributes to lessen health inequalities over the period 2010-2014.

With respect to ill-health inequalities, we find that age differences matter in explaining changing ill-health inequalities over the two time periods (2004-2010 and 2010-2014). Between 2004-2010, socio-economic inequalities among those who are below the age of 17 years, relative to older individuals, contribute to illhealth inequality. One can infer that children below the ages of 17 years lived in relatively poor households that likely had characteristics that increased the likelihood of them falling ill. We, however, observe the opposite result for the period 2010-2014. In contrast to 2004-2010 results, socio-economic inequalities among those who were aged above 30 years account for widening ill-health 
Table 3 Oaxaca-type decomposition of change in the health inequalities, 2004-2010 and 2010-2014

\begin{tabular}{|c|c|c|c|c|c|c|c|c|c|c|c|c|}
\hline & \multicolumn{6}{|c|}{$2004-2010$} & \multicolumn{6}{|c|}{$2010-2014$} \\
\hline & \multicolumn{3}{|c|}{ III-health status } & \multicolumn{3}{|c|}{ Disability } & \multicolumn{3}{|c|}{ III-health status } & \multicolumn{3}{|c|}{ Disability } \\
\hline & $\Delta C$ & se & $\%$ & $\Delta C$ & se & $\%$ & $\Delta C$ & se & $\%$ & $\Delta C$ & se & $\%$ \\
\hline $0-6$ yrs & -0.004 & 0.008 & -9.4 & -0.046 & 0.008 & 191.1 & -0.013 & 0.008 & -92.9 & 0.059 & 0.009 & 311.2 \\
\hline $6-17 y r s$ & -0.001 & 0.009 & -1.9 & 0.006 & 0.008 & -26.4 & -0.006 & 0.009 & -43.1 & 0.023 & 0.010 & 122.3 \\
\hline $18-30 y r s$ & 0.002 & 0.010 & 4.0 & 0.008 & 0.009 & -34.3 & -0.006 & 0.010 & -42.9 & 0.014 & 0.010 & 72.9 \\
\hline $31-45 y r s$ & 0.004 & 0.011 & 10.5 & -0.021 & 0.009 & 86.4 & 0.005 & 0.010 & 33.6 & -0.006 & 0.010 & -30.4 \\
\hline $46-64$ yrs & 0.003 & 0.013 & 7.4 & -0.039 & 0.010 & 159.7 & 0.002 & 0.012 & 12.2 & -0.018 & 0.011 & -96.3 \\
\hline Black African & -0.006 & 0.003 & -14.3 & -0.055 & 0.002 & 227.5 & -0.001 & 0.003 & -11.1 & 0.007 & 0.002 & 38.8 \\
\hline Indian & 0.000 & 0.016 & -0.9 & 0.000 & 0.007 & 0.5 & -0.004 & 0.016 & -32.6 & 0.000 & 0.007 & -0.5 \\
\hline White & 0.009 & 0.018 & 23.3 & 0.012 & 0.008 & -49.9 & 0.020 & 0.017 & 146.9 & 0.009 & 0.008 & 47.5 \\
\hline Single & 0.019 & 0.018 & 48.6 & 0.032 & 0.007 & -131.3 & 0.002 & 0.019 & 18.0 & -0.013 & 0.008 & -70.9 \\
\hline No schooling & 0.001 & 0.231 & 1.5 & 0.013 & 0.236 & -53.3 & 0.004 & 0.033 & 31.0 & -0.010 & 0.021 & -54.4 \\
\hline Less than diploma & 0.000 & 0.019 & -1.0 & -0.003 & 0.020 & 11.3 & 0.002 & 0.013 & 15.2 & 0.021 & 0.014 & 108.8 \\
\hline Diploma certificate & -0.001 & 0.018 & -3.7 & 0.022 & 0.019 & -91.5 & -0.003 & 0.011 & -20.7 & -0.015 & 0.012 & -77.9 \\
\hline Honours degree & 0.001 & 0.020 & 3.8 & 0.017 & 0.019 & -69.6 & -0.003 & 0.014 & -21.5 & -0.019 & 0.012 & -98.9 \\
\hline Employed & -0.002 & 0.040 & -4.1 & 0.063 & 0.025 & -261.5 & 0.004 & 0.036 & 26.0 & -0.012 & 0.020 & -62.6 \\
\hline Urban & 0.018 & 0.004 & 47.8 & 0.001 & 0.002 & -6.1 & 0.001 & 0.004 & 8.8 & 0.007 & 0.002 & 35.7 \\
\hline Western Cape & 0.014 & 0.005 & 35.3 & -0.018 & 0.003 & 75.8 & -0.005 & 0.005 & -40.7 & 0.004 & 0.003 & 22.1 \\
\hline Eastern Cape & -0.002 & 0.011 & -4.0 & 0.003 & 0.006 & -11.7 & -0.012 & 0.011 & -92.4 & 0.006 & 0.006 & 33.8 \\
\hline Northern cape & 0.000 & 0.008 & 1.0 & 0.000 & 0.006 & -0.5 & 0.000 & 0.009 & -0.1 & 0.000 & 0.007 & 0.6 \\
\hline Kwazulu-Natal & -0.011 & 0.010 & -27.6 & 0.007 & 0.006 & -29.7 & 0.002 & 0.010 & 15.9 & 0.004 & 0.007 & 23.4 \\
\hline North West & -0.011 & 0.010 & -27.6 & 0.001 & 0.006 & -5.4 & 0.000 & 0.010 & -2.7 & -0.003 & 0.007 & -14.5 \\
\hline Gauteng & 0.009 & 0.008 & 24.0 & -0.032 & 0.005 & 133.3 & 0.015 & 0.008 & 114.5 & 0.013 & 0.006 & 66.6 \\
\hline Mpumalanga & 0.000 & 0.009 & 0.6 & 0.002 & 0.005 & -8.6 & -0.001 & 0.009 & -9.8 & -0.001 & 0.006 & -4.0 \\
\hline Limpopo & -0.008 & 0.010 & -20.1 & -0.007 & 0.005 & 28.7 & 0.005 & 0.010 & 35.8 & 0.013 & 0.006 & 67.8 \\
\hline Grant recipient & 0.002 & 0.009 & 5.7 & 0.008 & 0.006 & -32.3 & 0.007 & 0.010 & 54.1 & -0.064 & 0.006 & -341.8 \\
\hline Female & 0.000 & 0.006 & 1.1 & 0.000 & 0.005 & -2.0 & 0.000 & 0.005 & -1.8 & 0.000 & 0.004 & 0.7 \\
\hline Total & 0.039 & & & -0.024 & & & 0.013 & & & 0.019 & & \\
\hline
\end{tabular}

inequalities over the period 2010-2014. This signals a relative improvement in socio-economic status among individuals in this age category.

While socio-economic inequalities among whites explain considerable reduction in ill-health inequality between 2010 and 2014, socio-economic inequalities among black Africans, relative to other population groups, worsen ill-health inequalities over the period 2004-2010. Also, ill-health inequalities over the period 2004-2010 were caused by socio-economic inequalities relating to educational attainment and employment status, as socio-economic inequalities among those who hold a diploma/certificate and those who are employed explain ill-health inequalities. On the other hand, socioeconomic inequalities among singles and those with little or no formal education contribute to changing ill-health inequalities over the period 2010-2014.
Notably, socio-economic inequalities relating to employment status, among those living in KwaZulu-Natal, North West and Limpopo, explain an improvement in illhealth inequalities in both time periods. For instance, the results suggest that socio-economic inequalities between the employed and unemployed worsened ill-health inequality over the period 2004-2010, while an improvement in ill-health inequalities, between 2010-2014, was caused by reduced socio-economic inequalities relating to employment status. On the other, ill-health inequalities worsened, based on increased socio-economic inequalities among those living in Eastern Cape.

Similar to ill-health results, we observe that age differences also matters in explaining differences in disability inequalities in the two time periods. Between 20102014, socio-economic inequalities among those who are below the age of 30 years contribute to changes in 
disability inequality. By contrast, socio-economic inequalities among those above the age of 30 years account for disability inequalities over the the period 2004-2010. Over the period 2010-2014, inequalities among those who are at least diploma certificate holders, employed, living in Free state and recipients of social grants explain disability inequality. Over the two time periods, socio-economic inequalities among black Africans, those having less than diploma, living in Western Cape, Gauteng and Limpopo provinces explain changing disability inequalities. For instance, while socio-economic inequalities among black Africans worsen disability inequalities between 2004-2010, disability inequalities were enhanced (became more pro-rich) by reduced socioeconomic inequalities among black Africans.

Overall, taking the changes in all the determinants of the health variables into account, the results suggest that the bulk of changes in ill-health inequalities, over the two time periods, are consistently explained by socioeconomic inequalities relating to employment status and provincial differences, which narrowed considerably over the studied periods. Relatedly, disability inequalities are largely explained by shrinking socio-economic inequalities within racial groups, educational attainment and provincial differences.

\section{Discussion}

This paper examines and compares the relative changes in socio-economic inequalities in health status, mainly ill-health status and disability, between 2004-2010 and 2010-2014 in post-apartheid South Africa, linking those changes to changes in social determinants. It emerged that socio-economic inequalities exist in the health variables and the inequalities widened over the period 20042010, but narrowed over the period 2010-2014. Socioeconomic inequalities, in favour of the better-off, also exist in disability over time. Over time, relatively richer individuals suffer from disability compared to their poorer counterparts. These findings resonate with existing evidence from similar studies carried out in developed and developing countries $[14,16,19,73,78-81]$, which suggest that rates of self-assessed poor health could be substantially higher among lower socio-economic groups, and that the magnitude of inequalities in SAH varies substantially across income distributions. In 17 European countries, almost no country consistently experienced a significant decline in either absolute or relative inequalities over time [7].

Also, in line with our findings, poor self-reported health is higher among lower socio-economic groups in South Africa [50, 51, 55]. Socio-economic inequalities in self-reported health tend to be greater among lower socio-economic groups [50]. Basically, propoor inequalities in ill-health status and disability found in this study are consistent with earlier studies, which found ill-health and disability to be more concentrated among the poor [48, 50, 51]. In addition, our analyses, which cover a more recent time period find a shift towards a pro-rich inequalities in ill-health and disability, over time.

More pertinently, our findings show that changes in inequalities in SDH play an important role in explaining changes in health over the two time periods, 20042010 and 2010-2014. Specifically, we find that social drivers of changing inequalities in ill-health status are related to changing socio-economic inequalities within racial groups, especially among black Africans, which widened considerably over time. Socio-economic inequalities in employment, educational attainment relating to diploma/certificate also explain inequalities in ill-health status over time. Moreover, socio-economic inequalities among those living in the Eastern Cape and KwaZulu-Natal consistently explain ill-health inequalities over the studied periods. Notably, disability inequalities are uniformly explained by inequalities in educational attainment, particularly having less than diploma, though such inequalities narrowed substantially. Socioeconomic inequalities among those residing in the Western Cape and Gauteng also consistently explained disability inequalities over the studied periods.

"Causes" of socio-economic inequalities in health include socio-economic status, education, urbanisation, geographics and housing. They are important factors that determine health inequity in most countries, especially in developing countries $[5,19,73,82,83]$. In line with the preceding studies, socio-economic factors are significant in explaining health inequality over time [7]. In South Africa, social protection and employment, knowledge and education, housing and infrastructure contribute to disparities in good SAH [48]. Relatedly, we find race, education and geography/provincial location to be key social drivers of health inequalities.

Changes in socio-economic inequalities in health can be explained by changes in inequalities in social determinants, namely education, income, housing and residential locations. Thus, social factors have an important influence in determining health status and explaining observed health inequalities over time[10, 19, 52, 84-88]. In addition to this study shedding more light on changing health inequalities in South Africa, the social determinantshealth inequalities nexus unraveled in this study further affirm and complement other related studies which have examined social gradients in health in South Africa $[21,23,33,48,50-57]$.

Overall, socio-economic inequalities relating to racial groups, geography/residential locations and educational attainment and employment status are found to be crucial in explaining inequalities in health over time. Although 
we did not establish any direct causal link, this finding, nonetheless, highlights the importance of the identified social factors in reducing health inequalities. Considering South Africa's past history of Apartheid and systemic racial discrimination, it is not too surprising that trends in inequalities in the identified social factors remain apparent in the analysis of SDH-health inequalities link. Plausibly, more concerted policy action and interventions to tackle further inequalities in social factors could help push the country towards a more equitable health care system. This might require new social-oriented policies emphasizing further reductions in inter- and intra- racial group inequalities and unemployment, improved access to education, especially for the previously disadvantaged groups, and more concrete and sustainable development programmes at provincial levels, while strengthening the existing ones that have proved to be somewhat effective. Available evidence suggests that, over the post-apartheid period, South Africa has maintained a reasonably equitable racial and gender balance in education and social grant receipt $[67,89,90]$. In particular, the non-contributory and unconditional grants have a strong racial dimension, with a sizeable proportion of previously disadvantaged groups as beneficiaries [91]. Despite all these polices and programmes, there remains a social gradient in key SDH in South Africa. Thus, there is more to be done to strengthen policy and institutions to further tackle socio-economic related health inequalities.

\section{Conclusion}

Using nationally representative data from the 2004, 2010 and 2014 General Household Surveys (GHSs), this research uncovers the relative changes in health inequalities over the second decade of post-apartheid South Africa. It also provides an explanation for changes in the social determinants of health that account for disparities in health over that period. The health indicators considered in the analysis include ill-health and disability. The concentration index regression model and the Oaxacatype decomposition of change in the concentration index were employed to achieve the stated objectives.

Notably, socio-economic related inequalities in health have been identified as one of the greatest challenges to public health in South Africa. Our findings show that a number of social factors, including education, employment status, provincial and racial differences need to be addressed in order to further tackle the avoidable and widely considered unacceptable socio-economic health inequalities in South African society. Evidence from this study explicitly supports the theories and views that the causes of social inequalities in health are multiple and inter-related. Actions to further tackle these, thus, need to be interconnected, intersectoral and across multiple intervention levels.
This study, therefore, recommends policies that are explicitly intersectoral in nature, which will entail multiple social interventions. The recommendations are aptly situated within the context of research on the typology of actions to tackle social inequalities in health [1, 92-94]. Tackling health inequalities through policies and interventions which are based on the underlying theory of how the action is expected to bring about the desired change [1]. The author proposes that the common interventions tend to fall into one of four main categories, which include: strengthening individuals, strengthening communities, improving living and working conditions and associated access to essential services, and promoting healthy macro-policies. Our research supports that view.

\section{Endnotes}

${ }^{1}$ Several articles have validated the use of wealth indices against external criteria. They conclude that they are good proxies for income differences [95-98]. A detailed description of the construction of the wealth index is contained in "Appendix A" section.

${ }^{2}$ Factor analysis (FA) is a multivariate statistical technique used to reduce the number of variables in a data set into a smaller number of 'dimensions' $[99,100]$.

\section{Appendix A}

\section{Mathematical derivation of wealth index}

In mathematical terms, from an initial set of $j$ correlated variables, FA creates uncorrelated indices or components where each component is a linear weighted combination of the initial variables. Following [68], given $j$ random variables $x_{1}, \ldots . ., x_{j}$, the FA wealth index can simply be represented as follows:

$$
F A_{1}=\lambda_{11} x_{1}+\lambda_{21} x_{2}+\lambda_{31} x_{3}+\ldots \ldots \ldots . .+\lambda_{j 1} x_{j} .
$$

In the case where the wealth variables, $x_{i}\{i=1 \ldots . . j\}$, are not standardised; to a mean of zero and variance of one, they are first standardized such that the equation for the first principal component is given by:

$$
\begin{aligned}
F A_{1}= & \lambda_{11}\left(\frac{x_{1}-\bar{x}_{1}}{s_{1}}\right)+\lambda_{21}\left(\frac{x_{2}-\bar{x}_{2}}{s_{2}}\right) \\
& +\lambda_{31}\left(\frac{x_{3}-\bar{x}_{3}}{s_{3}}\right)+\ldots . .+\lambda_{j 1}\left(\frac{x_{j}-\bar{x}_{j}}{s_{j}}\right) \\
= & \frac{\lambda_{11}}{s_{1}} x_{1}+\frac{\lambda_{21}}{s_{2}} x_{2}+\frac{\lambda_{31}}{s_{3}} x_{3}+\ldots \ldots \ldots . .+\frac{\lambda_{j 1}}{s_{j}} x_{j}-a .
\end{aligned}
$$

The coefficients $\lambda_{j 1}$ represent the elements of the eignevector $\lambda_{1}$ associated with the largest eigenvalue of the correlation matrix of the $x_{i}$ variables. The constant $a$ is the weighted sum of the means, which ensure that $F A_{1}$ has a 
mean of zero. In a more generic term, the wealth index, $F A_{i}$ for individual $j$ can thus be defined as:

$$
F A_{1}=\sum_{j}\left(\lambda_{j} \frac{\left(x_{j}-\bar{x}_{j}\right)}{s_{j}}\right) .
$$

\section{Abbreviations \\ GHS: General Household Survey; SAH: Self assessed health; SDH: Social determinants of health}

\section{Acknowledgements}

Not applicable.

\section{Funding}

Not applicable.

\section{Availability of data and materials}

The datasets analysed during the current study are publicly available and could be accessed at DataFirst repository - https://www.datafirst.uct.ac.za/ dataportal/index.php/catalog/central.

\section{Authors' contributions}

$\mathrm{KO}$ analysed and interpreted the results. SF supervised the entire research and was a major contributor in writing the manuscript. Both authors read and approved the final manuscript.

\section{Ethics approval and consent to participate}

Ethics approval was obtained from the Ethics committee, Faculty of Economic and Management Sciences, University of Pretoria.

\section{Consent for publication}

Not applicable.

\section{Competing interests}

The authors declare that they have no competing interests.

\section{Publisher's Note}

Springer Nature remains neutral with regard to jurisdictional claims in published maps and institutional affiliations.

Received: 5 May 2018 Accepted: 1 November 2018

\section{Published online: 11 December 2018}

\section{References}

1. Whitehead M. A typology of actions to tackle social inequalities in health. J Epidemiol Community Health. 2007;61 (6):473-8.

2. Arcaya MC, Arcaya AL, Subramanian S. Inequalities in health: Definitions, concepts, and theories. Glob Health Action. 2015;8(1):27106.

3. Graham H, Kelly MP. Health inequalities: concepts, frameworks and policy. In: Health Development Agency (HDA) Briefing Paper; 2004.

4. Kilbourne AM, Switzer G, Hyman K, Crowley-Matoka M, Fine MJ. Advancing health disparities research within the health care system: $\mathrm{A}$ conceptual framework. Am J Public Health. 2006;96(12):2113-21.

5. Balaj M, McNamara CL, Eikemo TA, Bambra C. The social determinants of inequalities in self-reported health in Europe: Findings from the European social survey (2014) special module on the social determinants of health. Eur J Public Health. 2017;27(1):107-14.

6. Devaux M. Income-related inequalities and inequities in health care services utilisation in 18 selected OECD countries. Eur J Health Econ. 2015;16(1):21-33.

7. Hu Y, van Lenthe FJ, Borsboom GJ, Looman CW, Bopp M, Burström B, Dzúrová D, Ekholm O, Klumbiene J, Lahelma E, et al. Trends in socioeconomic inequalities in self-assessed health in 17 European countries between 1990 and 2010. J Epidemiol Community Health. 2016;70(7):644-52

8. Owusu-Addo E, Renzaho AM, Smith BJ. The impact of cash transfers on social determinants of health and health inequalities in sub-Saharan Africa: A systematic review. Health Policy Plan. 2018;33(5):675-96.
9. Commission on Social Determinants of Health. Closing the Gap in a Generation: Health Equity through Action on the Social Determinants of Health. Technical report. Geneva: Geneva: World Health Organization; 2008.

10. Marmot M. Social determinants of health inequalities. Lancet. 2005:365(9464):1099-104.

11. Commission on Social Determinants of Health. Final Report of the Commission on Social Determinants of Health. Geneva: World Health Organization; 2008.

12. Marmot M, on Social Determinants of Health C, et al. Achieving health equity: From root causes to fair outcomes. Lancet. 2007;370(9593): 1153-63.

13. Wagstaff A. Research on equity, poverty and health outcomes: Lessons for the developing World. Washington, DC: World Bank; 2000.

14. Hakura MDS, Hussain MM, Newiak MM, Thakoor V, Yang MF Inequality, Gender Gaps and Economic Growth: Comparative Evidence for Sub-Saharan Africa. In: International Monetary Fund Working Paper, No 16/111; 2016.

15. Orach D, Garimoi C. Health equity: Challenges in low income countries. Afr Health Sci. 2009;9(2):49-51.

16. Braveman $P$, Tarimo E. Social inequalities in health within countries: Not only an issue for affluent nations. Soc Sci Med. 2002;54(11): 1621-35.

17. Boutayeb A, Helmert U. Social inequalities, regional disparities and health inequity in North African countries. Int J Equity Health. 2011;10(1):23.

18. Kabudula CW, Houle B, Collinson MA, Kahn K, Gómez-Olivé FX, Tollman S, Clark SJ. Socioeconomic differences in mortality in the antiretroviral therapy era in Agincourt, rural South Africa, 2001-13: A population surveillance analysis. Lancet Glob Health. 2017;5(9): 924-35.

19. Adeyanju O, Tubeuf S, Ensor T. Socio-economic inequalities in access to maternal and child healthcare in Nigeria: Changes over time and decomposition analysis. Health Policy Plan. 2017;32(8):1111-8.

20. Republic of South Africa Department of Health. National health insurance in South Africa: Policy paper. Pretoria: Republic of South Africa Department of Health; 2011.

21. Coovadia H, Jewkes R, Barron P, Sanders D, Mclntyre D. The health and health system of South Africa: Historical roots of current public health challenges. Lancet. 2009;374(9692):817-34.

22. African National Congress. A national health plan for South Africa. Johannesburg South Africa: Government Printer; 1994.

23. Chopra M, Lawn JE, Sanders D, Barron P, Karim SSA, Bradshaw D, Jewkes R, Karim QA, Flisher AJ, Mayosi BM, et al. Achieving the health Millennium Development Goals for South Africa: Challenges and priorities. Lancet. 2009:374(9694):1023-31.

24. Dhai A. Healthcare reform in South Africa: A step in the direction of social justice: editorial. S Afr J Bioeth Law. 2011;4(2):48-9.

25. Ruff $B$, Mzimba M, Hendrie S, Broomberg J. Reflections on health-care reforms in South Africa. J Public Health Policy. 201 1:32(1):184-92.

26. Govender V, Penn-Kekana L. Gender biases and discrimination: A review of health care interpersonal interactions. Glob Public Health. 2008;3(1): 90-103.

27. Harrison D. An overview of health and health care in South Africa 1994-2010: Priorities, progress and prospects for new gains; 2009. Washington, DC: Henry J Kaiser Family Foundation; 2012.

28. Van den Heever AM. South Africa's universal health coverage reforms in the post-apartheid period. Health Policy. 2016;120(12):1420-8.

29. Mayosi BM, Lawn JE, Van Niekerk A, Bradshaw D, Karim SSA, Coovadia HM, team LSA, et al. Health in South Africa: changes and challenges since 2009. Lancet. 2012;380(9858):2029-43.

30. Kleinert S, Horton R. South Africa's health: Departing for a better future? Lancet. 2009;374(9692):759-60.

31. Motsoaledi A. Progress and changes in the South African health sector. Lancet. 2012;380(9858):1969-70.

32. Young M. Private vs. Public Healthcare in South Africa. Kalamazoo: Western Michigan University, ScholarWorks at Western Michigan University (WMU); 2016.

33. Booysen F. Urban-rural inequalities in health care delivery in South Africa. Dev South Afr. 2003;20(5):659-73.

34. South Africa Constitution. Constitution of the Republic of South Africa Act, No. 108 of 1996. South Africa, Pretoria: Government printer; 1996. 
35. Burger R, Christian C. Access to health care in post-apartheid South Africa: Availability, affordability, acceptability. Health Econ Policy Law. 2018; 1-13 https://doi.org/10.1017/S1744133118000300.

36. Republic of South Africa Department of Health. National health insurance for South Africa: Towards universal health coverage. Pretoria, South Africa: Republic of South Africa Department of Health; 2015.

37. Mayosi BM, Flisher AJ, Lalloo UG, Sitas F, Tollman SM, Bradshaw D. The burden of non-communicable diseases in South Africa. Lancet. 2009;374(9693):934-47.

38. Bhorat $\mathrm{H}$, Van der Westhuizen C. Poverty, inequality and the nature of economic growth in South Africa. Testing democracy: Which way is South Africa going. 2010.

39. Meiring T, Kannemeyer C, Potgieter E. The gap between rich and poor: South African society's biggest divide depends on where you think you fit in. Southern Africa Labour and Development Research Unit (SALDRU) Working Paper Series 220(1) 1-31, University of Cape Town. 2018

40. World Bank. Overcoming Poverty and Inequality in South Africa: An Assessment of Drivers, Constraints and Opportunities. Washington DC: World Bank Publications, The World Bank Group; 2018.

41. Naledi T, Barron P, Schneider H. Primary health care in South Africa since 1994 and implications of the new vision for $\mathrm{PHC}$ re-engineering. South Africa: Health Systems Trust (HST); 2011

42. Mayosi BM, Benatar SR. Health and health care in South Africa-20 years after mandela. N Engl J Med. 2014;371(14):1344-53.

43. Harrison D. An overview of health and health care in South Africa 1994-2010: Priorities, progress and prospects for new gains. Discussion Document Commissioned by the Henry J. Kaiser Family Foundation to help inform the National Health Leaders' Retreat Muldersdrift, January 24-26 2010. Washington, DC: Henry J Kaiser Family Foundation; 2009.

44. Govender V, Chersich MF, Harris B, Alaba O, Ataguba JE, Nxumalo N, Goudge J. Moving towards universal coverage in South Africa? Lessons from a voluntary government insurance scheme. Glob Health Action. 2013;6(1):19253. https://doi.org/0.3402/gha.v6i0.19253.

45. Booysen S. Twenty years of South African democracy: Citizen views of human rights, governance and the political system. Washington DC; 2014.

46. Gilson L, Mclntyre D. Post-Apartheid challenges: Household access and use of health care in South Africa. Int J Health Serv. 2007;37(4):673-91.

47. Honda A, Ryan M, van Niekerk R, McIntyre D. Improving the public health sector in South Africa: Eliciting public preferences using a discrete choice experiment. Health Policy Plan. 2015;30(5):600-11.

48. Ataguba JE-O, Day C, McIntyre D. Explaining the role of the social determinants of health on health inequality in South Africa. Glob Health Action. 2015;8(1):1-11. https://doi.org/10.3402/gha.v8.28865.

49. Christian CS. Access in the South African public health system: Factors that influenced access to health care in the South African public sector during the last decade. South Africa: Master dissertation, Department of Economics, University of Western Cape; 2014.

50. Ataguba JE, Akazili J, McIntyre D. Socioeconomic-related health inequality in South Africa: Evidence from General Household Surveys. Int J Equity Health. 2011;10(48):1-10.

51. Zere $E$, Mclntyre D. Inequities in under-five child malnutrition in South Africa. Int J Equity Health. 2003;2(7):7.

52. Bradshaw D, Masiteng K, Nannan N. Health status and determinants. S Afr Health Rev. 2000;2000(1):89-124.

53. Bradshaw D. Determinants of health and their trends: Primary health care: in context. S Afr Health Rev. 2008;2008(1):51-69.

54. Harris B, Goudge J, Ataguba JE, Mclntyre D, Nxumalo N, Jikwana S, Chersich M. Inequities in access to health care in South Africa. J Public Health Policy. 2011;32(1):102-23.

55. Alaba O, Chola L. Socioeconomic inequalities in adult obesity prevalence in South Africa: A decomposition analysis. Int J Environ Res Public Health. 2014;11(3):3387-406.

56. Silal SP, Penn-Kekana L, Bärnighausen T, Schneider H. Local level inequalities in the use of hospital-based maternal delivery in rural South Africa. Glob Health. 2014;1(10):1-7.

57. Charasse-Pouélé $C$, Fournier M. Health disparities between racial groups in South Africa: A decomposition analysis. Soc Sci Med. 2006;62(11): 2897-914.

58. Obuaku-Igwe CC. Health inequality in South Africa: A systematic review. Afr Sociol Rev / Revue Africaine de Sociologie. 2015;19(2):96-131.
59. Oaxaca R. Male-female wage differentials in urban labor markets. Int Econ Rev. 1973;14(3):693-709.

60. Wagstaff A, Van Doorslaer E, Watanabe N. On decomposing the causes of health sector inequalities with an application to malnutrition inequalities in Vietnam. J Econ. 2003;112(1):207-23.

61. Statistics South Africa. General Household Survey 2004 [Statistical Release P0318 2005]. Pretoria: Statistics South Africa [producer], 2005. Pretoria: South African Data Archive, National Research Foundation [distributor], 2005. 2004.

62. Statistics South Africa. General Household Survey 2010 [Statistical Release P0318 2011]. Pretoria: Statistics South Africa [producer], 2011. Pretoria: South African Data Archive, National Research Foundation [distributor], 2011. 2010.

63. Statistics South Africa. General Household Survey 2014 [Statistical Release P0318 2015]. Pretoria: Statistics South Africa [producer], 2015. Pretoria: South African Data Archive, National Research Foundation [distributor], 2015. 2014.

64. Pillay-van Wyk V, Bradshaw D. Mortality and socioeconomic status: The vicious cycle between poverty and ill health. Lancet Glob Health. 2017;5(9):851-2.

65. Burgard SA, Treiman DJ. Trends and racial differences in infant mortality in South Africa. Soc Sci Med. 2006;62(5):1126-37.

66. Schiel R, Leibbrandt M, Lam D. Assessing the impact of social grants on inequality: A South African case study. In: Besley T, editor. Contemporary Issues in Development Economics. Chap. 8. Palgrave Macmillan, London: Springer; 2016. p. 112-35.

67. Patel L. Poverty, gender and social protection: Child support grants in Soweto, South Africa. J Policy Pract. 2012;11(1-2):106-20.

68. Wittenberg M, Leibbrandt M. Measuring inequality by asset indices: A general approach with application to South Africa. Rev Income Wealth. 2017;63(4):706-30

69. Wagstaff A, Paci P, Van Doorslaer E. On the measurement of inequalities in health. Soc Sci Med. 1991;33(5):545-57.

70. Kakwani N, Wagstaff A, Van Doorslaer E. Socioeconomic inequalities in health: Measurement, computation, and statistical inference. J Econ. 1997;77(1):87-103.

71. Erreygers G. Correcting the concentration index. J Health Econ. 2009;28(2):504-15.

72. Mackenbach JP, Kunst AE. Measuring the magnitude of socio-economic inequalities in health: An overview of available measures illustrated with two examples from Europe. Soc Sci Med. 1997;44(6):757-71.

73. Mackenbach JP, Stirbu I, Roskam A-JR, Schaap MM, Menvielle G, Leinsalu M, Kunst AE. Socioeconomic inequalities in health in 22 European countries. N Engl J Med. 2008;358(23):2468-81.

74. O'Donnell OA, Wagstaff A, et al. Analyzing Health Equity Using Household Survey Data: A Guide to Techniques and Their Implementation. Washington DC: World Bank Publications; 2008.

75. Solmi F, Von Wagner C, Kobayashi LC, Raine R, Wardle J, Morris S. Decomposing socio-economic inequality in colorectal cancer screening uptake in England. Soc Sci Med. 2015;134(7):76-86.

76. Wagstaff $A$. The bounds of the concentration index when the variable of interest is binary, with an application to immunization inequality. Health Econ. 2005; 14(4):429-32.

77. StataCorp. Stata Statistical Software: Release 14. Texas: College Station, TX StataCorp LP; 2015.

78. Marmot M, Friel S, Bell R, Houweling T, Taylor S. Closing the gap in a generation: Health equity through action on the social determinants of health. Lancet. 2008;372(9650):1661-9.

79. Ogura S, Jakovljevic M. Health Financing Constrained by Population Aging- An Opportunity to Learn from Japanese Experience/Finansiranje Zdravstvene Zaštite U Uslovima Starenja Popualcije-Prilika Da Učimo Na Japanskom Iskustvu. Serbian J Exp Clin Res. 2014;15(4):175-81.

80. Jakovljevic M, Getzen TE. Growth of global health spending share in low and middle income countries. Front Pharmacol. 2016;7(21).

81. Reading $C L$, Wien F. Health inequalities and the social determinants of Aboriginal peoples' health. Prince George, BC: National Collaborating Centre for Aboriginal Health; 2009.

82. Van Doorslaer Ev, Koolman X. Explaining the differences in income-related health inequalities across European countries. Health Econ. 2004;13(7):609-28. 
83. Reus-Pons M, Kibele EU, Janssen F. Differences in healthy life expectancy between older migrants and non-migrants in three European countries over time. Int J Public Health. 2017;62(5):531-40.

84. Hajizadeh M, Mitnitski A, Rockwood K. Socioeconomic gradient in health in Canada: Is the gap widening or narrowing?. Health Policy. 2016;120(9):1040-50.

85. Großschädl F, Stronegger WJ. Long-term trends in obesity among Austrian adults and its relation with the social gradient: 1973-2007. Eur J Public Health. 2013;23(2):306-12.

86. Cockerham W, Hamby B, Oates $G$. The social determinants of chronic disease. Am J Prev Med. 2017;52(1):5-12.

87. Adler NE, Glymour MM, Fielding J. Addressing social determinants of health and health inequalities. J Am Med Assoc. 2016;316(16):1641-2.

88. Novaković R, Cavelaars A, Geelen A, Nikolić M, Altaba II, Vinas BR, Ngo J, Golsorkhi M, Medina MW, Brzozowska A, et al. Socio-economic determinants of micronutrient intake and status in Europe: A systematic review. Public Health Nutr. 2014;17(5):1031-45.

89. Chapman K. Using social transfers to scale up equitable access to education and health services. London; 2006.

90. Goldblatt B. Gender and social assistance in the first decade of democracy: A case study of South Africa's Child Support Grant. Politikon: S Afr J Political Stud. 2005;32(2):239-57.

91. Taylor Commission, et al. Report of the Committee of Inquiry into a Comprehensive System of Social Security for South Africa. Pretoria: Department of Social Development; 2002.

92. Guglielmin M, Muntaner C, O'Campo P, Shankardass K. A Scoping Review of the Implementation of Health in All Policies at the Local Level: Elsevier; 2018

93. Shankardass K, Solar O, Murphy K, Greaves L, O'Campo P. A scoping review of intersectoral action for health equity involving governments. Int J Public Health. 2012;57(1):25-33.

94. Braveman P, Egerter S, Williams DR. The social determinants of health: Coming of age. Annu Rev Public Health. 2011;32:381-98.

95. Filmer D, Pritchett L. Estimating Wealth Effects without Expenditure Data-or Tears: An Application to Educational Enrollments in States of India. In: Policy Research Working Papers No. 1994; 1998.

96. Filmer D, Scott K. Assessing asset indices. Demography. 2012;49(1): 359-92.

97. Wittenberg M. Weighing the value of asset proxies: The case of the Body Mass Index in South Africa. Southern Africa Labour and Development Research Unit (SALDRU) Working paper 39, University of Cape Town. 2009.

98. Wittenberg M. Estimating expenditure impacts without expenditure data using asset proxies. Econ Lett. 2011;110(2):122-5.

99. Vyas S, Kumaranayake L. Constructing socio-economic status indices: How to use principal components analysis. Health Policy Plan. 2006;21(6):459-68.

100. Wittenberg M, Leibbrandt M. Measuring inequality by asset indices: A general approach with application to South Africa. Rev Income Wealth 2017;63(4):706-30

Ready to submit your research? Choose BMC and benefit from:

- fast, convenient online submission

- thorough peer review by experienced researchers in your field

- rapid publication on acceptance

- support for research data, including large and complex data types

- gold Open Access which fosters wider collaboration and increased citations

- maximum visibility for your research: over $100 \mathrm{M}$ website views per year

At BMC, research is always in progress.

Learn more biomedcentral.com/submission 